\title{
Sternoclavicular joint septic arthritis with chest wall abscess in a healthy adult: a case report
}

\author{
Yoshihito Tanaka*, Hisaaki Kato, Kunihiro Shirai, Yasuhiro Nakajima, Noriaki Yamada, Hideshi Okada, \\ Takahiro Yoshida, Izumi Toyoda and Shinji Ogura
}

\begin{abstract}
Background: Septic arthritis of the sternoclavicular joint is rare. It can be associated with serious complications such as osteomyelitis, chest wall abscess, and mediastinitis. In this report, we describe a case of an otherwise healthy adult with septic arthritis of the sternoclavicular joint with chest wall abscess.

Case presentation: A 68-year-old Japanese man presented to our hospital complaining of pain and erythema near the right sternoclavicular joint. Despite 1 week of oral antibiotics, his symptoms did not improve. Computed tomography revealed an abscess with air around the right pectoralis major muscle. After being transferred to a tertiary hospital, emergency surgery was performed. Operative findings included necrotic tissue around the right sternoclavicular joint and sternoclavicular joint destruction, which was debrided and packed open. Methicillinsusceptible Staphylococcus aureus was identified in blood and wound cultures. Negative pressure wound therapy and hyperbaric oxygen therapy were performed for infection control and wound healing. The patient's general condition improved, and good granulation tissue developed. The wound was closed using a V-Y flap on hospital day 48. The patient has been free of relapse for 3 years.
\end{abstract}

Conclusions: Septic arthritis of the sternoclavicular joint is an unusual infection, especially in otherwise healthy adults. Because it is associated with serious complications such as chest wall abscess, prompt diagnosis and appropriate treatment are required.

Keywords: Sternoclavicular joint septic arthritis, Chest wall abscess, Sepsis, Negative pressure wound therapy (NPWT), Hyperbaric oxygen therapy $\left(\mathrm{HBO}_{2}\right)$

\section{Background}

The sternoclavicular joint (SCJ) is an unusual site of septic arthritis. It is involved in only $0.5-1.0 \%$ of all joint infections and in less than $0.5 \%$ of joint infections in healthy patients [1-4]. Common risk factors for SCJ septic arthritis include intravenous drug use (21\%), infection at a distant site (15\%), diabetes mellitus (13\%), trauma (12\%), and an infected central venous line (9\%). No risk factors were found in $23 \%$ of patients with SCJ septic arthritis [1]. SCJ septic arthritis may lead to serious complications such as osteomyelitis [5], chest wall abscess [6-8], mediastinitis [9], or myositis [4]. Management of

\footnotetext{
* Correspondence: yoshihito910@gmail.com Department of Emergency and Disaster Medicine, Gifu University Hospital, 1-1 Yanagido, Gifu, Gifu 501-1194, Japan

SCJ septic arthritis consists of surgical debridement and intravenous antibiotics $[3,11]$. In this report, we describe a case of an otherwise healthy adult with SCJ septic arthritis with chest wall abscess.

\section{Case presentation}

A 68-year-old Japanese man presented to our hospital complaining of pain and erythema near the right SCJ. He had no risk factors for SCJ septic arthritis such as intravenous drug use, infection at a distant site, diabetes mellitus, trauma, laceration, or valvular heart disease. His past medical history and family history were noncontributory. Oral levofloxacin was started. One week later, he went to another hospital for medical care because his symptoms had not improved. Computed tomography 
(CT) of the chest revealed an abscess with air around the right pectoralis major muscle. He was transferred to a tertiary center for surgical care.

His physical examination revealed a body temperature of $39.3{ }^{\circ} \mathrm{C}$, heart rate of 100 beats per minute, and blood pressure of 140/80 mmHg. Signs of inflammation such as redness, swelling, and tenderness over the right SCJ (Fig. 1) were present. His white blood cell count was $14,060 / \mu \mathrm{l}$, and his C-reactive protein level was $17.5 \mathrm{mg} / \mathrm{dl}$ (Table 1). Repeat CT revealed an extensive abscess with air, involving the right pectoralis major muscle, right SCJ, retrosternal region, and right sternocleidomastoid muscle (Fig. 2).

Emergency surgical debridement was performed. The skin incision began at the right border of the thyroid and extended to the head of the right clavicle. Operative findings included necrosis of parts of the right pectoralis major and minor muscles and the right SCJ. The patient also had right SCJ destruction. The necrotic pectoralis major and minor muscles and parts of the clavicle and manubrium near the SCJ that had become detached were debrided. The cavity was irrigated and packed open (Fig. 3). An initial Gram stain revealed gram-positive cocci. Ampicillin/sulbactam, which was given preoperatively, was changed to cefazolin (6 g/day), gentamicin ( $320 \mathrm{mg} /$ day), and clindamycin $(2700 \mathrm{mg} /$ day $)$ after surgery. On hospital day 6, methicillin-susceptible Staphylococcus aureus was cultured from blood and wound specimens. Antibacterial therapy was tapered to intravenous cefazolin and continued for 6 weeks to treat osteomyelitis (Fig. 4). On

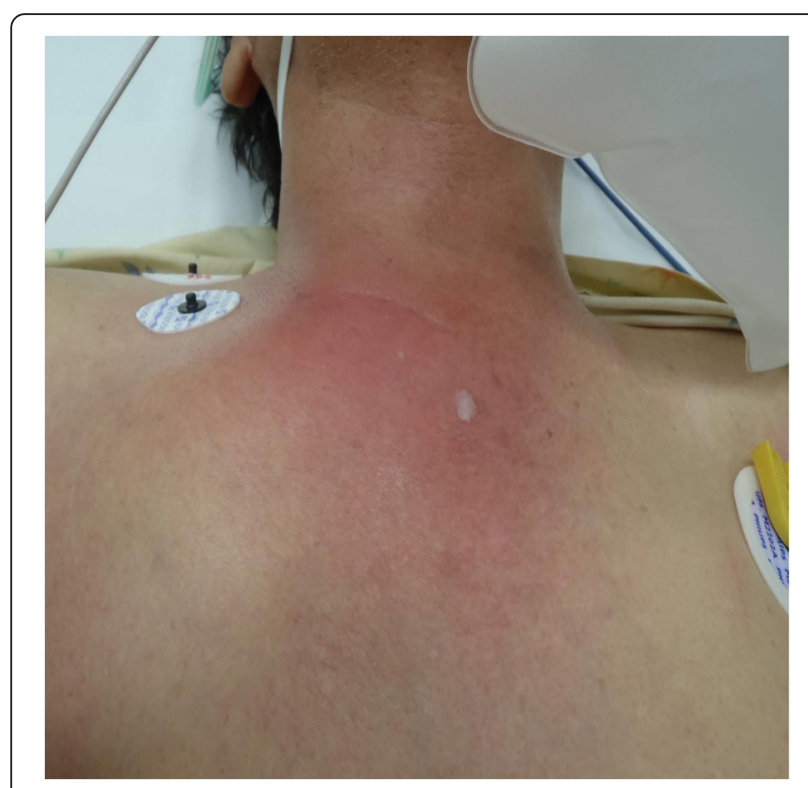

Fig. 1 Chest findings on admission. Redness and swelling of skin localizing to the sternoclavicular joint are shown postoperative day 10, residual necrotic tissue was debrided, and part of the wound edges was sutured together. After surgery, negative pressure wound therapy (NPWT) and hyperbaric oxygen therapy were performed for infection control and wound healing. The patient's general condition improved, and there was good granulation tissue formation. He was transferred to his hometown hospital, and the wound was closed using a V-Y flap on hospital day 48 . The patient has been free of relapse for 3 years.

\section{Discussion}

Septic arthritis of the SCJ is rare, involving only $0.5-1.0 \%$ of all joint infections. It occurs in less than $0.5 \%$ of otherwise healthy adults [1-4]. It may cause serious complications such as osteomyelitis [5], chest wall abscess [6-8], mediastinitis [9], or myositis [4], with an increased risk of irreversible tissue damage and possibly death $[4,10]$.

Among 180 cases of SCJ septic arthritis, Ross et al. identified the following predisposing risk factors: intravenous drug use (21\%), distant site of infection (15\%), diabetes mellitus (13\%), trauma (12\%), and infected central venous line $(9 \%)$. No risk factor was found in $23 \%$ of the patients [1]. The route of infection is often unknown, especially in otherwise healthy patients [3].

The clinical signs of SCJ septic arthritis are chest pain localizing to the SCJ (78 \%), fever (65\%), and shoulder pain (24\%). SCJ septic arthritis infrequently presents with neck pain $(2 \%)[1,2]$. Therefore, septic arthritis should always be considered in the differential diagnosis of chest and neck pain and fever.

CT or magnetic resonance imaging (MRI) should be performed routinely in all cases of SCJ arthritis [1] to determine the severity of the infection and guide the surgical strategy [12-14]. CT and MRI can demonstrate joint subluxation, joint destruction, periarticular inflammation, and SCJ abscess.

The rate of positive cultures with needle aspiration is $77 \%$, compared with $36 \%$ with surgical debridement and $13 \%$ with blood culture [1]. S. aureus is responsible for $49 \%$ of culture-positive infections, Pseudomonas aeruginosa for $10 \%$, Brucella melitensis for $7 \%$, and Escherichia coli for 5 \%. Mycobacterium tuberculosis infection occurs infrequently [1].

Management of SCJ septic arthritis consists of surgical debridement and intravenous antibiotics [3, 11]. Song et al. reported that complete SCJ resection and pectoralis flap closure resulted in no recurrences among patients with SCJ septic arthritis, while debridement and antibiotic therapy alone were associated with recurrence in five of six patients [12]. In our patient, because SCJ infection was limited to a small area, partial debridement was performed instead of complete resection. The cavity after debridement was relatively small, and NPWT was 
Table 1 Laboratory data on admission

\begin{tabular}{|c|c|}
\hline Laboratory parameters & Test results \\
\hline$\overline{\mathrm{TP}}$ & $4.2 \mathrm{~g} / \mathrm{dl}$ \\
\hline Alb & $2.2 \mathrm{~g} / \mathrm{dl}$ \\
\hline CPK & $127 \mathrm{IU} / \mathrm{L}$ \\
\hline AST & $45 \mathrm{IU} / \mathrm{L}$ \\
\hline ALT & $28 \mathrm{IU} / \mathrm{L}$ \\
\hline LDH & $239 \mathrm{IU} / \mathrm{L}$ \\
\hline ALP & $538 \mathrm{IU} / \mathrm{L}$ \\
\hline$Y$-GTP & $81 \mathrm{IU} / \mathrm{L}$ \\
\hline Amy & $16 \mathrm{IU} / \mathrm{L}$ \\
\hline Cre & $0.80 \mathrm{mg} / \mathrm{dl}$ \\
\hline BUN & $15.7 \mathrm{mg} / \mathrm{dl}$ \\
\hline TG & $122 \mathrm{mg} / \mathrm{dl}$ \\
\hline T-Chol & $85 \mathrm{mg} / \mathrm{dl}$ \\
\hline T-Bil & $2.9 \mathrm{mg} / \mathrm{dl}$ \\
\hline D-Bil & $1.7 \mathrm{mg} / \mathrm{dl}$ \\
\hline $\mathrm{Na}^{+}$ & $139 \mathrm{mEq} / \mathrm{L}$ \\
\hline $\mathrm{K}^{+}$ & $3.2 \mathrm{mEq} / \mathrm{L}$ \\
\hline $\mathrm{Cl}^{-}$ & $103 \mathrm{mEq} / \mathrm{L}$ \\
\hline $\mathrm{Mg}$ & $1.9 \mathrm{mg} / \mathrm{dl}$ \\
\hline $\mathrm{Ca}^{2+}$ & $7.1 \mathrm{mg} / \mathrm{dl}$ \\
\hline IP & $3.1 \mathrm{mg} / \mathrm{dl}$ \\
\hline CRP & $17.5 \mathrm{mg} / \mathrm{dl}$ \\
\hline $\mathrm{HbA1c}$ & $5.7 \%$ \\
\hline \multicolumn{2}{|l|}{ Arterial blood gas } \\
\hline $\mathrm{FiO}_{2}$ & 0.6 \\
\hline $\mathrm{pH}$ & 7.51 \\
\hline $\mathrm{pCO}_{2}$ & $33.0 \mathrm{mmHg}$ \\
\hline $\mathrm{pO}_{2}$ & $116.0 \mathrm{mmHg}$ \\
\hline $\mathrm{BE}$ & $3.2 \mathrm{mmol} / \mathrm{L}$ \\
\hline Lactate & $7 \mathrm{mg} / \mathrm{dl}$ \\
\hline WBC & $14,060 / \mu \mathrm{l}$ \\
\hline RBC & $356 \times 10^{4} / \mu \mathrm{l}$ \\
\hline $\mathrm{Hb}$ & $11.0 \mathrm{~g} / \mathrm{dl}$ \\
\hline $\mathrm{Hct}$ & $31.9 \%$ \\
\hline Plt & $14.6 \times 10^{4} / \mu l$ \\
\hline PT & 15.0 seconds \\
\hline $\mathrm{aPTT}$ & 33.5 seconds \\
\hline Fibrinogen & $683 \mathrm{mg} / \mathrm{dl}$ \\
\hline FDP & $14.2 \mu \mathrm{g} / \mathrm{dl}$ \\
\hline D-dimer & $7.2 \mu \mathrm{g} / \mathrm{dl}$ \\
\hline
\end{tabular}

Table 1 Laboratory data on admission (Continued)

\begin{tabular}{ll}
\hline AT-III & $49 \%$ \\
Antinuclear antibody & Negative \\
Rheumatoid factor & Negative
\end{tabular}

Alb albumin, $A L P$ alkaline phosphatase, $A L T$ alanine aminotransferase, $A m y$ amylase, aPTT activated partial thromboplastin time, AST aspartate aminotransferase, AT-III antithrombin III, BE base excess, BUN blood urea nitrogen, $\mathrm{Ca}^{2+}$ calcium, $\mathrm{Cl}^{-}$chloride, $\mathrm{CPK}$ creatine phosphokinase, $\mathrm{Cre}$ creatinine, CRP C-reactive protein, D-Bil direct bilirubin, FDP fibrin degradation products, $\mathrm{FiO}_{2}$ fraction of inspired oxygen, $\gamma$-GTP $\gamma$-glutamyl transferase, $\mathrm{Hb}$ hemoglobin, HbA1c glycated hemoglobin A1c, Hct hematocrit, IP inorganic phosphorus, $\mathrm{K}^{+}$potassium, $\mathrm{LDH}$ lactate dehydrogenase, $\mathrm{Mg}$ magnesium, $\mathrm{Na}^{+}$sodium, $p \mathrm{CO}_{2}$ partial pressure of carbon dioxide, Plt platelets, $p \mathrm{O}_{2}$ partial pressure of oxygen, $P T$ prothrombin time, $R B C$ red blood cells, $T$-Bil total bilirubin, $T$-Chol total cholesterol, $T G$ triglycerides, $T P$ total protein, $W B C$ white blood cells

performed for wound granulation. After methicillinsusceptible $S$. aureus was identified in blood and wound cultures, broad-spectrum intravenous antimicrobial therapy was switched to intravenous cefazolin, which was continued for 6 weeks to treat osteomyelitis.

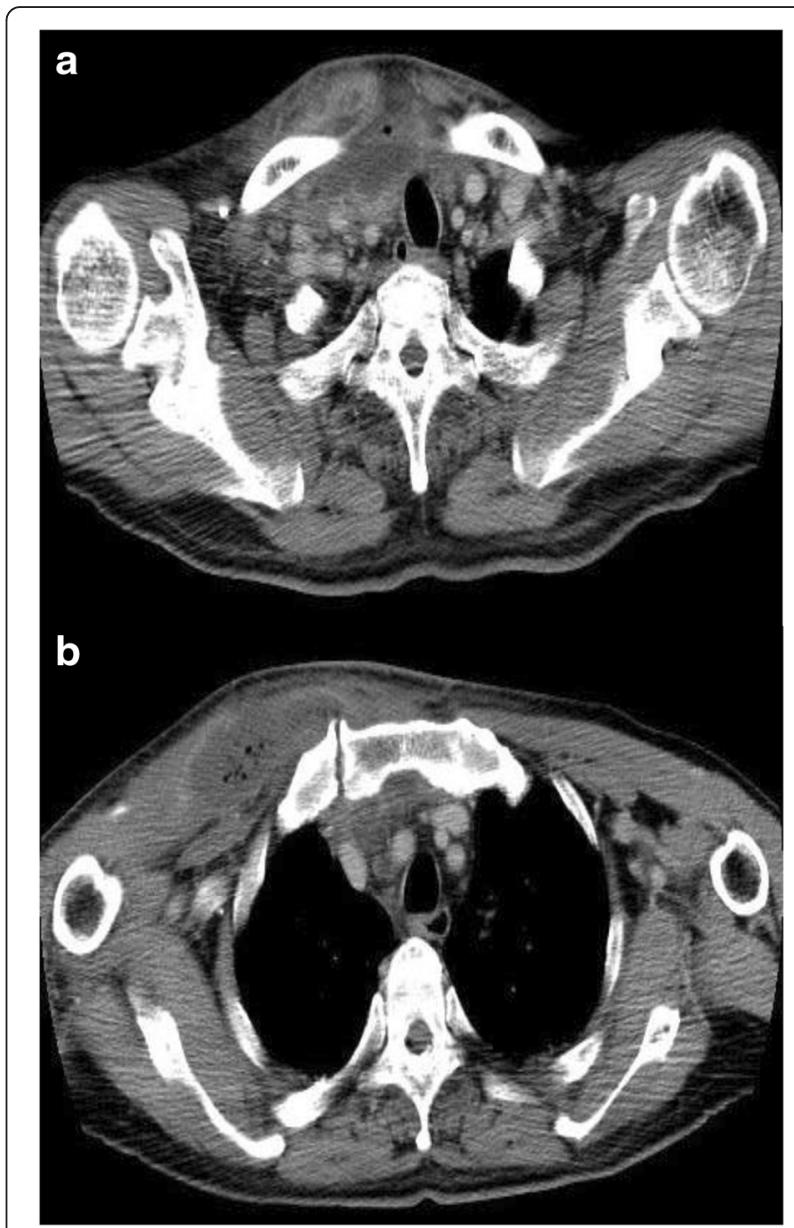

Fig. 2 Computed tomographic scans of the chest on admission. Computed tomography of the chest detected an abscess with air located below the thyroid gland and involving the right pectoral major muscle around the right sternoclavicular joint $(\mathbf{a}, \mathbf{b})$, as well as disaggregation of the right sternoclavicular joint (b) 


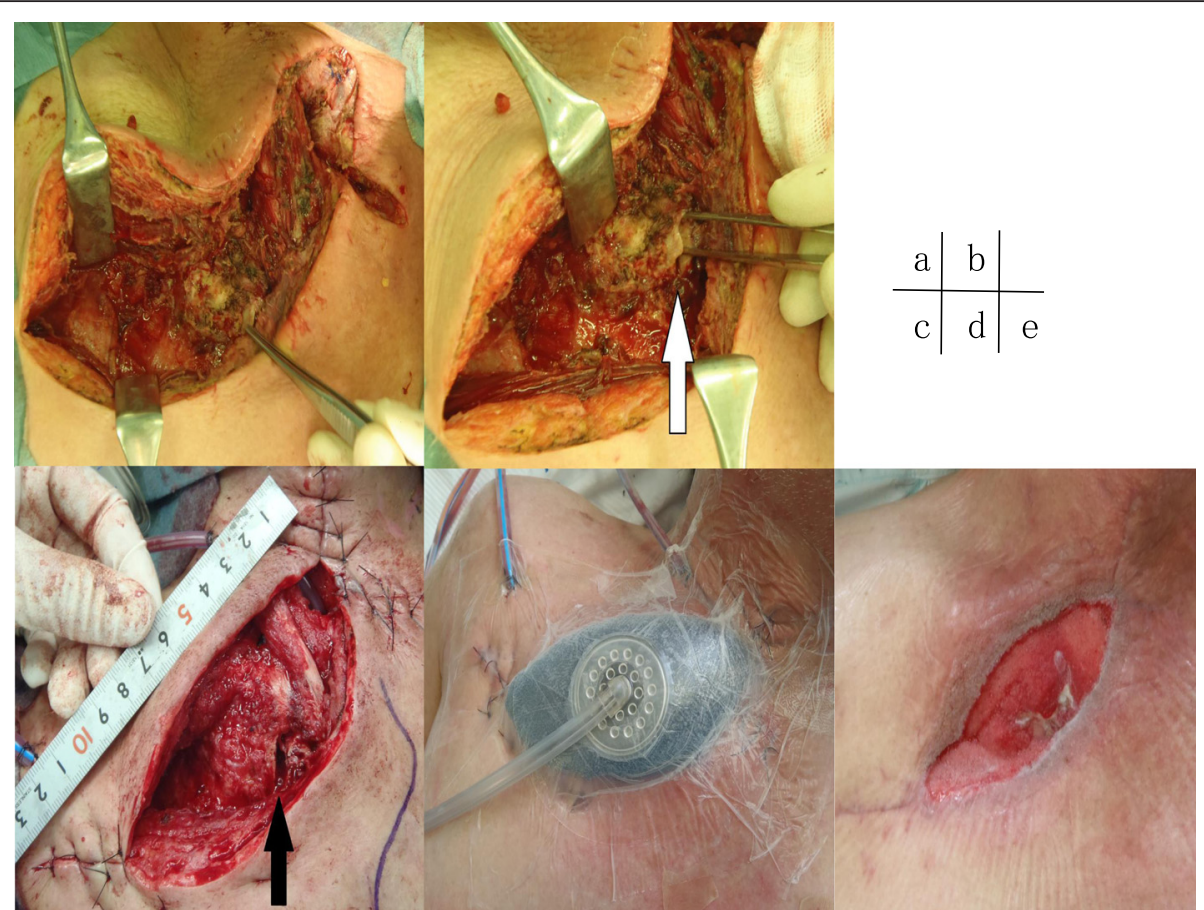

Fig. 3 Wound-related findings. Operative findings on the day of admission $(\mathbf{a}, \mathbf{b})$ were necrotizing tissue around the sternoclavicular joint and the joint destruction (white arrow). When we debrided residual necrotizing tissue on postoperative day 10, the sternoclavicular joint was still exposed (black arrow) (c). We introduced negative pressure wound therapy on postoperative day 11 (d). On postoperative day 37, good granulation was observed (e)

\section{Conclusions}

SCJ septic arthritis is a rare infection, especially in healthy adults. Because SCJ septic arthritis is associated with a risk of serious complications such as chest wall abscess, prompt diagnosis and appropriate surgical and antibacterial treatment are required.

\section{Consent}

Written informed consent was obtained from the patient for publication of this case report and any accompanying images. A copy of the written consent is available for review by the Editor-in-Chief of this journal.

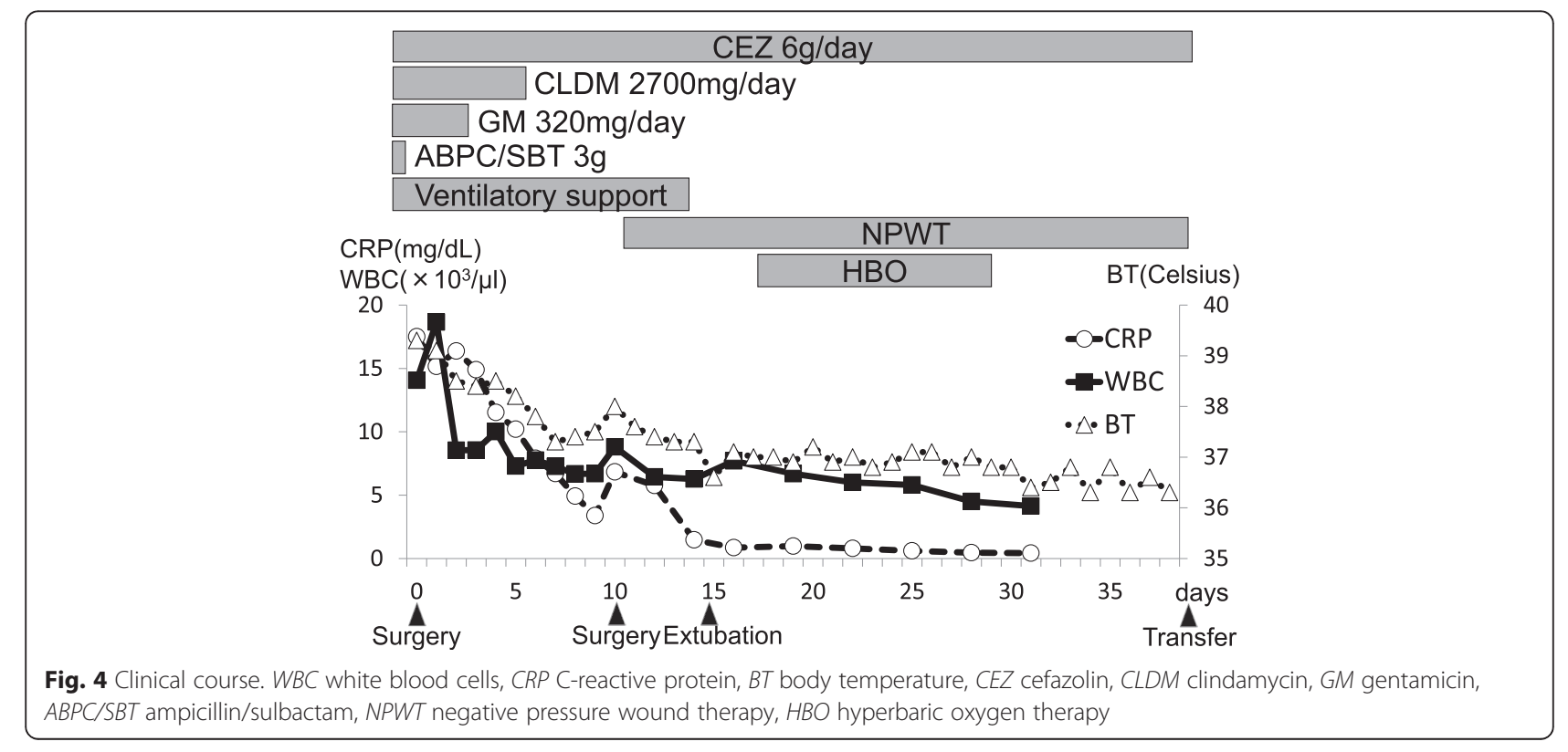




\section{Abbreviations}

ABPC/SBT: ampicillin/sulbactam; Alb: albumin; ALP: alkaline phosphatase; ALT: alanine aminotransferase; Amy: amylase; aPTT: activated partial thromboplastin time; AST: aspartate aminotransferase; AT-III: antithrombin III; BE: base excess; BT: body temperature; BUN: blood urea nitrogen; $\mathrm{Ca}^{2+}$ : calcium; CEZ: cefazolin; $\mathrm{Cl}^{-}$: chloride; CLDM: clindamycin; CPK: creatine phosphokinase; Cre: creatinine; CRP: C-reactive protein; CT: computed tomography; D-Bil: direct bilirubin; FDP: fibrin degradation products; $\mathrm{FiO}_{2}$ : fraction of inspired oxygen; GM: gentamicin; $\gamma$-GTP: $\gamma$-glutamyl transferase; Hb: hemoglobin; HbA1c: glycated hemoglobin A1c; HBO: hyperbaric oxygen therapy; Hct: hematocrit; IP: inorganic phosphorus; $\mathrm{K}$ +: potassium; LDH: lactate dehydrogenase; Mg: magnesium; MRI: magnetic resonance imaging; $\mathrm{Na}^{+}$: sodium; NPWT: negative pressure wound therapy; $\mathrm{pCO}_{2}$ : partial pressure of carbon dioxide; Plt: platelets; $\mathrm{pO}_{2}$ : partial pressure of oxygen; PT: prothrombin time; RBC: red blood cells; SCJ: sternoclavicular joint; T-Bil: total bilirubin; T-Chol: total cholesterol; TG: triglycerides; TP: total protein; WBC: white blood cells.

\section{Competing interests}

The authors declare that they have no competing interests.

\section{Authors' contributions}

YT analyzed and interpreted the clinical data, wrote the case report, and revised the manuscript. HK, KS, YN, NY, HO, TY, IT, and $\mathrm{SO}$ supervised the case. All authors read and approved the final manuscript.

Received: 16 February 2015 Accepted: 2 March 2016

Published online: 26 March 2016

\section{References}

1. Ross JJ, Shamsuddin H. Sternoclavicular septic arthritis: review of 180 cases. Medicine. 2004;83:139-48.

2. Yood RA, Goldenberg DL. Sternoclavicular joint arthritis. Arthritis Rheum 1980;23:232-9.

3. Bar-Natan M, Salai M, Sidi Y. Sternoclavicular infectious arthritis in previously healthy adults. Semin Arthritis Rheum. 2002;32:189-95.

4. Crisostomo RA et al. Septic sternoclavicular joint: a case report. Arch Phys Med Rehabil. 2008;89:884-6.

5. Tecce PM, Fishman EK. Spiral CT with multiplanar reconstruction in the diagnosis of sternoclavicular osteomyelitis. Skelet Radiol. 1995;24:275-81.

6. Lindhoudt DV, Velan F, Ott H. Abscess formation in sternoclavicular septic arthritis. J Rheumatol. 1989;16:413-4.

7. Wohlgethan JR, Newberg AH, Reed JI. The risk of abscess from sternoclavicular septic arthritis. J Rheumatol. 1988:15:1302-6.

8. Yasuda T, Tamura K, Fujiwara M. Tuberculous arthritis of the sternoclavicular joint: a report of three cases. J Bone Joint Surg Am. 1995;77:136-9.

9. Pollack MS et al. Staphylococcal mediastinitis due to sternoclavicular pyarthrosis. J Comput Assist Tomogr. 1990;14:924-7.

10. Fordham $\mathrm{S}$ et al. Optimal management of sternoclavicular septic arthritis. Eur J Emerg Med. 2009;228:275-8.

11. Haddad M, Maziak DE, Shamji FM. Spontaneous sternoclavicular joint infections. Ann Thorac Surg. 2002;74:1225-7.

12. Song HK, Guy TS, Kaiser LR, et al. Current presentation and optimal surgical management of sternoclavicular joint infections. Ann Thorac Surg. 2002;73:427-31

13. Burkhart HM, Deschamps C, Allen MS, et al. Surgical management of sternoclavicular joint infections. J Thorac Cardiovasc Surg. 2003;125:945-9.

14. Nusselt T, Klinger HM, Freche S, Schultz W, Baums MH. Surgical management of sternoclavicular septic arthritis. Arch Orthop Trauma Surg. 2011;131:319-23.

\section{Submit your next manuscript to BioMed Central and we will help you at every step:}

- We accept pre-submission inquiries

- Our selector tool helps you to find the most relevant journal

- We provide round the clock customer support

- Convenient online submission

- Thorough peer review

- Inclusion in PubMed and all major indexing services

- Maximum visibility for your research

Submit your manuscript at www.biomedcentral.com/submit
Biomed Central 